\title{
INDICAÇÕES GEOGRÁFICAS COMO ESTRATÉGIA DE DESENVOLVIMENTO TERRITORIAL: uMA ANÁlise ENTRE Brasil E EUROPA
}

\author{
Darlan Pez WOCIECHOSKI
}

\begin{abstract}
RESUMO: O presente trabalho visa analisar as Indicações Geográficas enquanto política de desenvolvimento territorial no contexto brasileiro e europeu com base no conceito de economia mundo capitalista, a fim de discutir o surgimento de uma forma sofisticada de manutenção da hierarquia mundial de divisão racial do trabalho. Consideramos, para tanto, que as indicações geográficas representam uma nova forma de manutenção do capital; isso porque, mesmo provocando dinamização e aumento da renda em alguns territórios rurais da semiperiferia que anteriormente eram desfavorecidos pela ótica produtivista agrícola, estes ganhos serão, a priori, inferiores aos ganhos dos territórios de países do núcleo central (Europa) devido à dominação cultural atrelada às suas identidades étnico-raciais.
\end{abstract}

PALAVRAS-CHAVE: Indicações geográficas. Desenvolvimento territorial. Divisão mundial racial do trabalho.

\section{Introdução}

Nas duas últimas décadas ocorreu a ascensão da abordagem territorial do desenvolvimento no plano político-institucional e na academia, com vistas a oferecer uma visão alternativa ao desenvolvimento econômico clássico e às suas estratégias (SACCO DOS ANJOS; CALDAS, 2014). Dentre essas alternativas, tem

\footnotetext{
USP - Universidade de São Paulo. Programa de Pós-Graduação em Educação. São Paulo - SP _ Brasil. 05508-040 - darlanpez@usp.br. https://orcid.org/0000-0002-6766-4405.
} 
se destacado o uso de selos de Indicações Geográficas (IGs) para agregação de valor a produtos e serviços de territórios rurais (VELLOSO, 2008).

As IGs e, em certa medida, a abordagem territorial têm sua maior expressão nas experiências europeias para os seus respectivos espaços rurais e, em meio a diversas análises e controvérsias ao seu respeito, ainda são apresentadas no Brasil e alhures como capazes de fornecer subsídios para o desenvolvimento territorial (SACCO DOS ANJOS; AGUILAR CRIADO; CALDAS, 2013).

A problemática que se forma quando estamos inseridos em uma perspectiva histórica mundial dos estudos do desenvolvimento é a formação de algumas invariantes ao longo do tempo/espaços que mantém a sobrevivência do sistema capitalista (BRAUDEL, 1987; WALLERSTEIN, 1974). De modo geral, a hipótese principal deste trabalho está fundamentada no conceito histórico de Economia Mundo Capitalista para analisar a reprodução de uma hierarquia mundial de poder e de divisão racial de trabalho entre países (BRAUDEL, 1987; WALLERSTEIN, 1974; QUIJANO, 2000), através do uso das IGs, no contexto das políticas de desenvolvimento territorial (VELLOSO, 2008; VALENTE et al., 2012; SACCO DOS ANJOS; AGUILAR CRIADO; CALDAS, 2013; CALDAS, 2014).

Desde já, se antevê, a partir da ótica do conceito de Economia Mundo Capitalista, que políticas públicas de desenvolvimento provavelmente não podem colaborar na superação do capitalismo (BRAUDEL, 1987; WALLERSTEIN, 1974; QUIJANO, 2000). Dessa forma, a contribuição maior deste trabalho revelase, sobretudo, na percepção e discussão da perversidade do uso das IGs como estratégia de legitimação de um fluxo de capitais para países centrais. Subjacente a esta importância, estão as contribuições aos estudos rurais da corrente teórica aos quais Fernand Braudel (1987), Immanuel Wallerstein (1974) e Aníbal Quijano (2000) estão relacionados.

A fim de sustentar esta hipótese, além da presente introdução, este trabalho está dividido em mais três seções. A segunda seção busca apresentar e situar de maneira breve o debate sobre desenvolvimento dos espaços rurais e do papel das Indicações Geográficas, com ênfase na descrição do contexto europeu e brasileiro (VELLOSO, 2008; VALENTE et al., 2012; SACCO DOS ANJOS; AGUILAR CRIADO; CALDAS, 2013; CALDAS, 2014). A terceira seção é reservada para análise e discussão da IG como estratégia para desenvolvimento territorial, com base no conceito de Economia Mundo Capitalista (BRAUDEL, 1987; WALLERSTEIN, 1974), de modo a privilegiar a discussão sobre a divisão racial do trabalho (QUIJANO, 2000) entre Brasil e Europa. Por fim, a última seção reserva-se às considerações finais. 


\section{Indicaçōes geográficas como estratégia de desenvolvimento territorial: uma análise entre Brasil e Europa}

\section{Do desenvolvimento agrícola ao desenvolvimento territorial - rompimentos e paralelismos}

No âmbito dos estudos rurais é perceptível a inclinação das políticas e teorias de desenvolvimento territorial, em grande medida, aos agricultores com propriedades pequenas e médias, enquanto que, os modelos e valores economicistas-produtivistas do desenvolvimento agrícola privilegiam os produtores rurais de grandes extensões de terra (BUAINAIN et al, 2013; MATTEI, 2014; FAVARETO, 2014). São duas linhas teóricas e políticas com visões antagônicas. Um olhar a partir do pós-guerra até o momento atual representa ser suficiente para compreender este embate de visões de desenvolvimento que promovem/trabalham com visões antagônicas de espaço rural e, inclusive, do próprio desenvolvimento - como veremos na sequência.

Após a Segunda Guerra Mundial, em meio aos processos de independência e consolidação dos últimos Estados-Nação ocorreu a potencialização de polarizações e binarismos no direcionamento do pensamento político e teórico mundial (QUIJANO, 2000). Foram os casos da polarização entre Estados Unidos da América e da União das Repúblicas Socialistas Soviéticas, e, também, a invenção do desenvolvimento/ subdesenvolvimento, conforme revelaram os estudos de Furtado (1992), sob a égide da teoria Centro-Periferia de Raúl Prebisch (COUTO, 2007). Nesse contexto, novas nações procuravam se desenvolver com respaldo da então dominante teoria da modernização que fundamentou o modelo de desenvolvimento em estágios de crescimento e a perspectiva ou lógica dualista (RUTTAN, 1975).

Nesse sentido, aos países considerados subdesenvolvidos, defendia-se seguir o receituário modernizador desses modelos de desenvolvimento, pois se acreditava que as condições econômicas e sociais do Atlântico Norte poderiam ser universalizadas para outras sociedades (FURTADO, 1992). No que diz respeito ao espaço rural para essa teoria de desenvolvimento, este era estritamente compreendido como setor de produção agropecuária e como atrasado/arcaico no pensamento então dominante; à medida que o setor urbano-industrial era considerado moderno (VEIGA, 2002; WANDERLEY, 2000). Ou seja, a hegemônica visão de desenvolvimento ou crescimento econômico no período entre 1950 e 1970 era compreendida como sinônimo de industrialização e no espaço rural também (NAVARRO, 2001). Assim surge o modelo de desenvolvimento agrícola por meio da modernização tecnológica da agricultura e pecuária (RUTTAN, 1975). Com isso, as lavouras eram vistas como indústrias e suas estratégias traduziam-se no uso intensivo de novas tecnologias, como os agroquímicos e a mecanização de todo o processo produtivo, com vistas ao aumento de produtividade de grãos (commodities) para exportação.

Essa visão de desenvolvimento perdeu o protagonismo e começou a dividir espaço com outras formas a partir dos anos de 1980 (SCHNEIDER, 2004). Isso ocorreu, conforme o autor, por questões sociais, econômicas e ambientais decorrentes 
da crise da modernização da agricultura. Com isso, um novo paradigma nos estudos e políticas de desenvolvimento foi formado no entorno dos agricultores familiares, com intuito de romper com a visão setorial agropecuária atrelada estritamente ao espaço rural e, sobretudo, para resolver problemas interligados a este grupo social como "a erradicação da pobreza rural, a questão do protagonismo dos atores sociais e sua participação política, o território como unidade de referência e a preocupação central com a sustentabilidade ambiental" (SCHNEIDER, 2004, p. 7).

A quebra da hegemonia da concepção econômica-agrícola foi sentida primeiramente na Europa com a difusão dos resultados do trabalho O Futuro do Mundo Rural; o qual, não só constatou que o espaço rural "não pode estar simplesmente reduzido ao cumprimento de funções produtivas, devendo jogar um papel decisivo no tema do equilíbrio ecológico e do suporte às atividades de ócio e recreação", mas, igualmente, reorientou a Política Agrária Comum da Comunidade Econômica Europeia (atual União Europeia). (SACCO DOS ANJOS, 2003, p. 72). No caso brasileiro, os resultados do Projeto Rurbano, coordenado pelo professor José Graziano da Silva (SILVA, 2001), foram igualmente emblemáticos, pois ampararam o discurso de criação da Secretaria de Desenvolvimento Territorial no âmbito do Governo Federal (SACCO DOS ANJOS; CALDAS 2014).

Nessa nova perspectiva de intervenção no meio rural, é estimulada na esfera produtiva a "incorporação de valor aos produtos no seio do próprio estabelecimento ou da exploração de novas linhas de atuação com ênfase nos chamados 'nichos de mercado' (locais, denominações de origem ou produtos especiais)" (SACCO DOS ANJOS, 2003, p. 73, aspas no original). Como destaca Pecqueur (2005), o desenvolvimento territorial deve nascer a partir de uma entidade produtiva enraizada num espaço geográfico até anterior à busca da especificação de produtos e, com isso, as IGs configuram-se como um exemplo de selos para diferenciação de produtos agropecuários (VELLOSO, 2008) para comercialização nas chamadas "cadeias agroalimentares curtas" (RENTING; MARSDEN; BANKS, 2003).

Em suma, algumas políticas de desenvolvimento territorial, trabalham, em uma de suas frentes, com o fomento da agregação de valor pela diferenciação dos produtos agropecuários por meio da identidade cultural do território de origem (certificados através de selos) (VELLOSO, 2008), enquanto que em concepções teóricas e políticas agrícola-produtivistas, há uma perspectiva predominante de ganhos através da produção de commodities em larga escala (BUAINAIN et al, 2013). Apesar destas diferenciações, ao levarmos em conta as origens e apropriações supracitadas, percebemos que tanto os produtos com selos de certificação de origem quanto as commodities são reguladas por uma economia mundial e, consequentemente, tem relação com a manutenção de uma hierarquia mundial na divisão de trabalho. 


\section{Indicaçōes geográficas como estratégia de desenvolvimento territorial: uma análise entre Brasil e Europa}

\section{Indicação Geográfica: a criação de monopólio através da cultura (raça/etnia)}

O reconhecimento de características peculiares de produtos e serviços conferidos pela localização geográfica é uma prática relativamente antiga em alguns lugares do mundo, ao passo que, conjuntamente com o prestígio de produtos provenientes desses locais específicos adveio, também, a proliferação imediata de falsificações (CALDAS, 2014; VALENTE et al., 2012). Ainda para os autores, os modos de distinguir a autenticidade dos produtos destacados pela sua origem evoluíram com os anos sob os mais diversos signos. Como exemplos, encontramos a jurisdição do queijo francês Roquefort criada em 1666 e o marco legal dos vinhos portugueses da região do Douro em 1756, nos seus respectivos países (VALENTE et al., 2012).

Ademais, a Europa, nos anos de 1970, adotou de modo mais abrangente e sistemático à etiquetação e delimitação de territórios produtores, ao passo que, em 2011 havia próximo de três mil registros, entre bebidas e produtos alimentares com IG (VALENTE et al., 2012). Enquanto que o Brasil apresenta, com a assegurada proporcionalidade, uma quantidade irrisória se comparada à Europa (VALENTE et al., 2012). Conforme Caldas (2014, p. 6), "o desenvolvimento mais significativo da cultura e regulamentação técnica e legal das Indicações Geográficas, indiscutivelmente, é o continente europeu".

A definição de IGs brasileiras são semelhantes às adotadas pela União Europeia (VALENTE et al., 2012) e são regulamentadas no Brasil por meio da Lei No 9279/1996 (BRASIL, 1996) que disciplina direitos e obrigações relativos à propriedade industrial. A semelhança da legislação brasileira sobre IG com a da União Europeia não é casuística e tem como antecedente uma promoção de organismos mundiais por meio de acordos que regulam o comércio desses produtos conforme o breve histórico exposto por Caldas (2014). Amiúde, descreve o autor, as convenções entre países sobre o comércio e propriedade intelectual remontam: à Convenção da União de Paris (CUP) em 1883; ao Acordo de Madri em 1981; ao Office International de la Vigne et du Vin (OIV) em 1947; ao Acordo de Lisboa de 1958, do qual o Brasil é signatário; e à Rodada do Uruguai de Negociações Comerciais Multilaterais (General Agrement of Trade and Tarifs - GATT) em 1994, que foi decisiva para promulgar e incorporar as decisões estabelecidas na legislação brasileira de propriedade intelectual (CALDAS, 2014). Nesta rodada

foram instituídas importantes resoluções que vieram a se formalizar nos Acordos sobre os Aspectos dos Direitos de Propriedade Intelectual relacionados ao Comércio (ADPIC), que estabelece a proteção jurídica internacional dos direitos da propriedade intelectual, do qual as Indicações Geográficas fazem parte. Dessa 


\section{Darlan Pez Wociechoski}

forma, o território é visto pela OMC como propriedade intelectual. (CALDAS, 2014, p. 4).

Para tanto, dentre os objetivos das IGs, avulta-se o papel de diferenciação dos produtos de modo a agregar valor e assegurar o retorno das vantagens comerciais à região de origem. Caldas (2014) assinala que as IGs possibilitam ao território integrar-se no mundo da competitividade comercial. "Entretanto exigem do produtor a responsabilidade de produzir com qualidade, de seduzir o cliente e de despertar o sentimento de confiança do consumidor em relação à procedência do produto." (CALDAS, 2014, p. 6).

As IGs operam, nesse sentido, como uma ferramenta para valorizar as tradições dos territórios como sinal distintivo de mercado e, dessa forma, é considerada uma forma de desenvolvimento local e/ou territorial, mesmo não havendo sido concebidas com essa função (VELLOSO, 2008). Com base na abordagem de cadeias agroalimentares curtas de Renting, Marsden e Banks (2003), compreende-se que esses selos visam, principalmente, adentrar em áreas de mercados próximos e fora de suas respectivas regiões, ou seja, estão fora do mercado local - da venda direta do produtor ao consumidor final. Contudo, mesmo admitindo esses diferentes níveis mercantis, desde Braudel (1987, p. 30), é preciso considerar a existência de uma "economia que liga entre si os diferentes mercados do mundo" e que permite o funcionamento do sistema capitalista atual. Dessa forma, o capitalismo funciona através da manipulação ou falseamento de preços arbitrariamente fixados por "intermediários e 'atravessadores"" que monopolizam de fato ou de direito os mercados e que, com isso, garantem para si grandes lucros - parafraseando Braudel (1987, p. 31).

Nesse sentido, podemos compreender que o capitalismo é o avesso da economia de mercado, pois, enquanto esta última procura promover abertamente a competição entre vendedores num espaço local, de modo que acaba por aproximar a venda dos produtos ao seu valor de uso, o capitalismo trabalha numa lógica obscura e monopolista que promove expressivos ganhos por meio das longas cadeias mercantis que atravessam diferentes países (BRAUDEL, 1987). Como recorda o autor "Falar em cadeias mercantis significa falar de uma divisão social estendida do trabalho, a qual, ao longo do desenvolvimento do capitalismo histórico, tornou-se cada vez mais funcional e mais ampliada geograficamente, e ao mesmo tempo cada vez mais hierarquizada. (BRAUDEL, 1987, p. 28).

Para Wallerstein (1974), tal hierarquização provoca uma distribuição extremamente desigual entre os países, porque alguns deles ficam em determinados períodos com as áreas (cadeias) mais rentáveis e/ou com os setores mais rentáveis das cadeias em detrimento de outros. Segundo o conceito de economia-mundo capitalista de Braudel (1987, p. 53-54), essa distribuição desigual direciona o fluxo de capitais para um pólo/núcleo central - "representado por uma cidade 


\section{Indicaçōes geográficas como estratégia de desenvolvimento territorial: uma análise entre Brasil e Europa}

dominante" -, circundado por zonas intermediárias e por zonas periféricas que recebem, respectiva e proporcionalmente, remunerações menores das trocas mercantis pelos seus serviços e recursos.

$\mathrm{Na}$ esteira desta compreensão, Wallerstein (1974, p. 404 - tradução livre) questiona: "como é possível politicamente que tal sistema persista [?]. Por que a maioria dos que são explorados simplesmente subjuga a minoria que tira benefícios desproporcionais?". Oportunamente, o mesmo autor responde que existem três mecanismos principais que permitem uma relativa estabilidade política deste sistema; são eles: 1) "a concentração do poder militar nas mãos das forças dominantes"; 2) "a onipresença de um compromisso ideológico com o sistema como um todo"; 3 ) "a divisão da maioria em um estrato inferior maior e um estrato médio menor" (WALLERSTEIN, 1974, p. 404 - tradução livre).

Na continuidade da compreensão dos mecanismos sistêmicos do capitalismo, quando os países não estão em um sistema político comum ocorre uma

estratificação "cultural" [que] não é tão simples, porque a ausência de um único sistema político significa a concentração dos papéis econômicos verticalmente em vez de horizontalmente em todo o sistema. A solução é então ter três tipos de estados, com pressões para a homogeneização cultural dentro de cada um deles assim além do estrato superior dos estados-núcleo e do estrato inferior dos estados periféricos, existe um estrato médio de semiperiféricos. (WALLERSTEIN, 1974, p. 405 - tradução livre).

Como o próprio autor destaca, a semiperiferia tem um papel político central na manutenção do sistema, porque "significa precisamente que o estrato superior não é confrontado com a oposição unificada de todos os outros, porque o estrato médio é ao mesmo tempo explorador e explorado" (WALLERSTEIN, 1974, p. 405 - tradução livre). Assim, a semiperiferia comporta-se como "classe média" e revela outra face deste sistema: "Tanto as classes, quanto os grupos étnicos [...] são fenômenos das economias mundiais" (WALLERSTEIN, 1974, p. 405 - tradução livre). Ainda sobre este aspecto, mas a respeito da categoria raça nas relações de poder mundial, com a descoberta da América, Aníbal Quijano descreve:

E na medida em que as relações sociais que estavam se configurando eram relações de dominação, tais identidades foram associadas com hierarquias, lugares e funções sociais correspondentes, como constitutivas delas e, em consequência, ao padrão de dominação colonial que se impunha. Em outras palavras, raça e identidade racial foram estabelecidas como instrumentos de classificação social básica da população. [...] Na América, a ideia de raça foi um modo de outorgar legitimidade as relações de dominação imposta pela conquista. [...] Assim, ambos 
os elementos, raça e divisão do trabalho, ficaram estruturalmente associados e reforçavam-se mutuamente, apesar de que nenhum dos dois era necessariamente dependente um do outro para existir ou para mudar. Deste modo se impôs uma sistemática divisão racial do trabalho. (QUIJANO, 2000, p. 1-3 - tradução nossa).

Compreendido este pensamento que atravessa Braudel (1987), Wallerstein (1974) e Quijano (2000), bem como reconhecidas as características das indicações geográficas como estratégia de desenvolvimento territorial (VELLOSO, 2008), centramo-nos em avançar na discussão em dois pontos interligados: as cadeias mercantis de bens de luxo e a divisão racial do trabalho.

As teorias de Braudel (1987) e Wallerstein (1974) parecem ser suficientes para explicar e descrever as cadeias mercantis de bens comuns onde os monopólios são criados por agentes econômicos de modo, por vezes, obscuros. No entanto, é preciso ampliar para questões atuais, como no caso dos produtos com selos de IG que participam de uma concorrência ou competição monopolística; uma forma de concorrência imperfeita a priori, e são considerados bens de luxo ${ }^{1}$.

Ao considerarmos que os produtos e serviços são consagrados pelos aspectos sensoriais interligados com a cultura do território de origem, há, desde o descobrimento da América, como advoga Quijano (2000), um padrão intersubjetivo eurocêntrico. Tal padrão atribui as virtudes aos europeus e os vícios aos demais.

Neste contexto, pode ser percebida uma situação em que as hierarquias são mantidas, mas de modo mais perverso porque, se em um primeiro momento da história o desenvolvimento econômico com as cadeias industriais típicas e de distribuição desigual de ganhos era/é justificado e legitimado por uma supremacia de conhecimentos e tecnologias das sociedades do primeiro mundo, nas primeiras décadas do século XXI, o capitalismo se aproveita da inércia de uma supremacia cultural - eurocentrismo (QUIJANO, 2000) - para continuar como destino do fluxo de capitais gerados pelo comércio de produtos com indicação geográfica de origem.

Corrobora com tal compreensão de que os países semiperiféricos e periféricos iniciam desfavorecidos na disputa com os países do núcleo central europeu pelo valor de seus produtos com IGs, a perspectiva teórica sobre os campos de Bourdieu (1983), pois, os agentes entrantes no campo, que aceitam as condições do jogo são incialmente desprovidos de capital específico. Além disso, é provável que as IGs promovam a dinamização das economias nos seus respectivos territórios, mas, em princípio, esse conjunto não ultrapasse o nível político sistêmico relegado a semiperiferia (WALLERSTEIN, 1974).

Sobre bens de luxo e concorrência monopolística, vide: Nunes (2009). 


\section{Indicaçōes geográficas como estratégia de desenvolvimento territorial: uma análise entre Brasil e Europa}

Outro ponto complexo que avulta neste contexto é a associação entre classe social e nação. Os produtos e serviços com IG da semiperiferia inegavelmente trazem ganhos para sua nação e território de origem, mas não o suficiente para superar os ganhos dos países do núcleo central. Ou seja, ora a semiperiferia comporta-se como exploradora, ora como explorada, aproximando-se significativamente de um comportamento típico da classe média (WALLERSTEIN, 1974).

Não parece producente aos países periféricos que não chegaram a padrões de produtividade agropecuária e de distribuição de alimentos para toda a sua população adentrarem na seara de diferenciação e qualificação dos mesmos, tão pouco questionar a legitimidade da distribuição de ganhos e de produção de alimentos desigual, porque encontram nos países semiperiféricos - como aquiesce Wallerstein (1974) - um mote mais próximo a ser perseguido.

Enfim, é importante perceber que, dessa maneira, ocorre uma sofisticada divisão racial do trabalho (QUIJANO, 2000), pois, para que haja essa concorrência monopolista é necessária a existência de produtos e serviços com qualidades diferentes (NUNES, 2009); - neste caso, vinculadas às identidades culturais/ étnicas/raciais distintas. Assim, a cultura do núcleo central europeu tem seus produtos e serviços com IGs mais valorizados, e por isso, seu trabalho é mais rentável. Da mesma forma, em geral, os trabalhadores brasileiros da semiperiferia, possivelmente, tenham ganhos médios inferiores no horizonte atual de análise, e que os países periféricos nem cogitem a possibilidade de entrar na competição comercial com sua cultura e com seu poder político-diplomático nos organismos mundiais sanitários, porque, nos termos de Bourdieu (1983), não possuem capital específico para tanto.

\section{Considerações Finais}

A partir do exposto, parecem promissoras pistas empíricas que trabalhem comparativamente com o fluxo de capitais do comércio mundial de produtos com indicações geográficas; e detalhando, por exemplo, a escala de apreciação comparativa entre produtos e serviços originados de territórios de população predominantemente branca com outros territórios de população não-branca. Nessa mesma linha, propicia-se a oportunidade para pesquisas que explorem a formação de hierarquias intranacionais. Uma vez que, de forma emblemática, o local do primeiro selo registrado no país - o Vale dos Vinhedos da Serra Gaúcha - é também a região com um dos melhores Índices de Desenvolvimento Humano do Rio Grande do Sul e do Brasil. 


\title{
GeOGRAPHICAL INDICATIONS AS A TERRITORIAL DEVELOPMENT STRATEGY: A BRAUDELIAN ANALYSIS BETWEEN BRAZIL AND EUROPE
}

\begin{abstract}
The present work seeks to analyze Geographical Indications as a territorial development policy in Brazilian and European contexts based on the concept of a capitalist world economy, in order to discuss the emergence of a sophisticated way of maintaining the worldwide hierarchy of racial division of labor. Accordingly, the theoretical foundations of Fernand Braudel, Immanuel Wallerstein and Anibal Quijano are used. We consider, therefore, that geographical indications represent a new form of capital maintenance, since although they generate dynamization and increased income in some semi-peripheral rural territories that were previously disadvantaged by agricultures 'productivist views, these gains are, a priori, lower than the gains of territories from countries of the central nucleus (Europe) that are due to the cultural domination linked to old-world ethnic-racial identities.
\end{abstract}

KEYWORDS: Geographical indications. Territorial development. Racial world division of labor.

\section{INDICACIONES GEOGRÁFICAS COMO ESTRATEGIA DE DESARROLLO TERRITORIAL: UN ANÁLISIS BRAUDELIANA ENTRE BRASIL Y EUROPA}

\begin{abstract}
RESUMEN: En este trabajo se pretende analizar las Indicaciones Geográficas como política de desarrollo territorial en el contexto brasileño y europeo con base en el concepto de economía mundo capitalista, a fin de discutir el surgimiento de una forma sofisticada de mantenimiento de la jerarquía mundial de división racial del trabajo. Con eso, se utilizaron los fundamentos teóricos de Fernand Braudel, Immanuel Wallerstein y Aníbal Quijano. Consideramos, de esta manera, que las indicaciones geográficas representan una nueva forma de mantenimiento del capital; puesto que, mismo provocando dinamización y aumento de la renta en algunos territorios rurales de la semiperiferia que anteriormente eran desfavorecidos por la óptica productivista agrícola, estas ganancias serán, a priori, inferiores a las ganancias de los territorios de los países del núcleo central (Europa) debido a la dominación cultural vinculada a las identidades étnico-raciales del viejo mundo.
\end{abstract}

PALABRAS CLAVE: Indicaciones geográficas. Desarrollo territorial. División mundial racial del trabajo. 


\section{Indicaçōes geográficas como estratégia de desenvolvimento territorial: uma análise entre Brasil e Europa}

\section{REFERÊNCIAS}

BOURDIEU, Pierre. Alta Costura e Alta Cultura. In: BOURDIEU, Pierre. Questões de sociologia. Rio de Janeiro: Trad. Miguel Serras Pereira. Marco Zero, p. 205 - 215. 1983.

BRASIL. Lei no 9279 de 14 de maio de 1996. Regula direitos e obrigações relativos à propriedade industrial. Diário Oficial [da] República Federativa do Brasil, Brasília, DF, 15 maio, 1996. Disponível em: <http://www.planalto.gov.br/ccivil_03/LEIS/L9279.htm>. Acessado em: 12 jul. 2017.

BRAUDEL, Fernand. A dinâmica do capitalismo. Rio de Janeiro: Rocco, 1987.

BUAINAIN, Antônio Márcio; ALVES, Eliseu; SILVEIRA, José Maria Ferreira Jardim da; NAVARRO, Zander. Sete teses sobre o mundo rural brasileiro. Revista de política agrícola, v. $22, n^{\circ} 2$, p. $105-121,2013$.

CALDAS, Alcides dos Santos. Indicações Geográficas: territórios seletivos do capital. In: XII SEMINÁRIO INTERNACIONAL DA REDE GLOBALIZAÇÃO E TERRITÓRIO, 2014, Salvador. Anais do XIII Seminário Internacional da RII. Salvador, 2014.

COUTO, Joaquim Miguel. O pensamento desenvolvimentista de Raúl Prebisch. Economia e Sociedade. Campinas, v. 16, nº. 1 (29), p. 45-64, 2007.

FAVARETO, Arilson da Silva. Um contraponto à tese da "argentinização" do desenvolvimento rural no Brasil. In: BUAINAIN, Antônio Márcio; ALVES, Eliseu; SILVEIRA, José Maria Ferreira Jardim da; NAVARRO, Zander. (Org.). O mundo rural no Brasil do século 21 - a formação de um novo padrão agrário e agrícola. 1 ed. Brasília: Embrapa, 2014, v. 1, p. 1101-1124.

FURTADO, Celso. O subdesenvolvimento revisitado. Economia e Sociedade, v. 1, $\mathrm{n}^{\mathrm{o}} 1$, p. 05-19, 1992.

MATTEI, Lauro. Considerações acerca de teses recentes sobre o mundo rural brasileiro. Revista de economia e sociologia rural, v. 52, p. 105-124, 2014.

NAVARRO, Zander. Desenvolvimento rural no Brasil: os limites do passado e os caminhos do futuro. Estudos avançados, v. 15, n. 43, p. 83-100, 2001.

NUNES, William Ricardo Barbieri. O mercado de bens de luxo. 2009. 78f. Trabalho de Conclusão de Graduação (Ciências Econômicas) - Faculdade de Ciências Econômicas, Universidade Federal do Rio Grande do Sul, Porto Alegre, 2009.

PECQUEUR, Bernard. O desenvolvimento territorial: uma nova abordagem dos processos de desenvolvimento para as economias do Sul. Raízes, Campina Grande, UFCG, v.24, n.1/2, p.10-22, jan./dez., 2005. 
QUIJANO, Aníbal. Colonialidad del poder, eurocentrismo y América Latina. In: LANDER, E. (Org.). La colonialidad del saber: eurocentrismo y ciências sociales. Perspectivas Latinoamericanas. Buenos Aires, Argentina: CLACSO, Consejo Latinoamericano de Ciencias Sociales, 2000.

RENTING, Henk; MARSDEN, Terry; BANKS, Jo. Understanding alternative food networks: exploring the role of short food supply chains in rural development. Environment and Planning A, v. 35, n. 3, p. 393-412, 2003.

RUTTAN, Vernon Wesley. Teorias de crescimento em estágios, modelos de economia dualista e política de desenvolvimento agrícola. In: ARAÚJO, Paulo Fernando Cidade de; SCHUH, George Edward. (Org.). Desenvolvimento da agricultura: natureza do processo e modelos dualistas. São Paulo: Pioneira, 1975.

SACCO DOS ANJOS, Flávio. Agricultura familiar, pluriatividade e desenvolvimento rural no Sul do Brasil. Pelotas: Egufpel, 2003.

SACCO DOS ANJOS, Flávio; AGUILAR CRIADO, Encarnación; CALDAS, Nádia Velleda. Indicações geográficas e desenvolvimento territorial: um diálogo entre a realidade europeia e brasileira. Dados, Revista de Ciências Sociais, v. 56, n. 1, p. 207-236, 2013.

SACCO DOS ANJOS, Flávio; CALDAS, Nádia Velleda . Da medida do rural ao rural sob medida: representações sociais em perspectiva. História, Ciências, Saúde-Manguinhos (Impresso), v. 21, p. 385-402, 2014.

SCHNEIDER, Sérgio. A abordagem territorial do desenvolvimento rural e suas articulações externas. Sociologias, Porto Alegre, n. 11, p. 88-125, jan.jun. 2004

SILVA, José Graziano da. Velhos e novos mitos do rural brasileiro. Estudos avançados, v. $15, \mathrm{n}^{\mathrm{o}} 43$, p. 37-50, 2001.

VALENTE, Maria Emília Rodrigues; PEREZ, Ronaldo; RAMOS, Afonso Mota; CHAVES, José Benício Paes. Indicação geográfica de alimentos e bebidas no Brasil e na União Europeia. Ciência Rural, v. 42, n. 3, p. 551-558, 2012.

VEIGA, José Eli da. A face territorial do desenvolvimento. Revista Internacional de Desenvolvimento Local, v. 3, n ${ }^{0}$ 5, p. 5-19, 2002.

VELLOSO, Carolina Quiumento. Indicação geográfica e desenvolvimento territorial sustentável: a atuação dos atores sociais nas dinâmicas de desenvolvimento territorial a partir da ligação do produto ao território (um estudo de caso em Urussanga, SC). 2008. 166f. Dissertação (Mestrado em Agroecossistemas) - Centro de Ciências Agrárias, Universidade Federal de Santa Catarina, SC. 
WALLERSTEIN, Immanuel. The rise and future demise of the world capitalist system: Concepts for comparative analysis. Comparative studies in society and history, v. 16, n. 4, p. 387-415, 1974.

WANDERLEY, Maria de Nazareth Baudel. A emergência de uma nova ruralidade nas sociedades modernas avançadas - o "rural" como espaço singular e ator coletivo. Estudos Sociedade e Agricultura, Rio de Janeiro, n. 15, p. 87-146, 2000.

Recebido em 21/08/2017.

Aprovado em 09/11/2018. 
